\title{
SEMENTES DE GIRASSOL: OBSERVAÇOES PRELIMINARES SOBRE O TESTE DE ENVELHECIMENTO RÁPIDO
}

\author{
JOCELY ANDREUCCETTI MAEDA $\left({ }^{2}\right)$, LUIZ FERNANDES RAZERA $\left({ }^{2}\right)$ \\ e MARIA REGINA GONÇALVES UNGARO $\left({ }^{3}\right)$
}

\begin{abstract}
RESUMO
Seis lotes de sementes de girassol foram submetidos ao teste de envelhecimento rápido, empregando-se $42^{\circ} \mathrm{C}$ de temperatura e aproximadamente $100 \%$ de umidade relativa, por períodos de $24,48,72,96$ e 120 horas. $O$ teste de envelhecimento rápido foi eficiente na avaliaçāo da qualidade fisiológica das sementes de girassol ensaiadas. Entre os períodos testados, o de 72 horas foi aquele que melhor discriminou níveis de vigor entre lotes que não diferiram quanto à capacidade germinativa.
\end{abstract}

Termos de indexaçâo: sementes; girassol; vigor; envelhecimento.

\section{INTRODUCAX̃o}

A qualidade fisiológica é de fundamental importância na avaliação e comparação de diferentes lotes de sementes. $O$ teste de germinação constituiu, por muito tempo, a única medida de avaliação da qualidade fisiológica da semente. Ele fornece condições ideais de germinação (SOMERS et alii,

( $\left.{ }^{1}\right)$ Trabalho apresentado no III Congresso Brasileiro de Sementes, realizado em Campinas (SP), 26-30 de setembro de 1983. Recebido para publicação a 9 de janeiro de 1984 .

$\left.{ }^{2}{ }^{2}\right)$ Seção đe Sementes, Instituto Agronômico (LAC), Caixa Postal 28, 13100 - Campinas (SP).

(3) Seção de Oleaginosas, IAC. 
1983; ZIMMERMAN \& ZIMMER, 1978) que, na maioria das vezes, não ocorrem no campo. Este teste pode não discriminar lotes que apresentem diferentes níveis de deterioração, visto que a perda da capacidade germinativa é a última e mais desastrosa conseqüência do processo de deterioração da semente. Assim, lotes do mesmo poder germinativo podem apresentar diferentes níveis de vigor, sem que o teste de germinação consiga detectar.

Com os avanços verificados em tecnologia de sementes, outras características passaram a ser investigadas, com o objetivo de avaliar a qualidade fisiológica da semente. Originou-se, então, o conceito de vigor de sementes e, para avaliá-lo, grande número de testes têm sido sugeridos. Entre estes, o de envelhecimento rápido tem sido o mais utilizado em diferentes espécies de sementes; no entanto, não é conhecida a sua aplicabilidade em girassol. Ele se caracteriza por submeter as sementes a condições adversas, ou seja, umidade relativa e temperatura elevadas, por determinado periodo de tempo (GOMES, 1970), acarretando aceleração bastante pronunciada dos processos normais de deterioração de sementes.

O presente trabalho foi conduzido com o objetivo de verificar a resposta de sementes (aquênios) de girassol (Helianthus annuus L.) ao teste de envelhecimento rápido, bem como determinar o período de permanência na câmara de envelhecimento que melhor discrimine as diferenças de nivel de vigor entre lotes que apresentem poder germinativo semelhante.

\section{MATERIAL E MÉTODOS}

Seis diferentes lotes de sementes, provenientes do Banco de Germoplasma da Seção de Oleaginosas do IAC, foram submetidos ao teste de envelhecimento rápido, utilizando os seguintes cultivares: Airelli (safra 1980/81), Florestal Cambá (1981/82), IAC Anhandy (safras 1981/82 e 1982/83), Uruguai (safras 1978/79 e 1980/81).

O teste em questão foi realizado em julho de 1983 , em câmara de envelhecimento rápido, com temperatura constante de $42^{\circ} \mathrm{C}$ e umidade relativa de aproximadamente $100 \%$, empregando os perfodos de $0,24,48,96$ e 120 horas de permanência na mesma.

Após cada um dos periodos, foram tomadas oito repetiçбes de 50 sementes de cada um dos lotes, procedendo-se, em seguida, ao teste padrão de germinação, nas condiçðes prescritas pelas Regras para Análise de Sementes (BRASIL, 1976).

Os resultados obtidos, em porcentagem, foram transformados em arco seno $\sqrt{\%}$, para efeito de análise estatística, sendo a comparação entre as médias feita pelo teste de Tukey (GOMES, 1970). 


\section{RESULTADOS E DISCUSSÃO}

A análise dos resultados obtidos (Quadro 1) mostrou que o teste de envelhecimento rápido parece ser eficiente na avaliação da qualidade fisiológica de sementes de girassol. De maneira geral, o poder germinativo de todos os lotes estudados decresceu à medida que se aumentou o período de permanência na câmara de envelhecimento. $O$ período de 72 horas foi o que melhor discriminou os niveis de vigor entre lotes que não diferiram quanto à capacidade germinativa. Dessa maneira, os seis lotes que pelo teste de germinação haviam sido classificados em apenas três níveis de qualidade fisiológica, com 72 horas de envelhecimento, ficaram organizados em cinco níveis de vigor de sementes.

QUADRO 1 - Resultados do teste de envelhecimento rápido $\left(42^{\circ} \mathrm{C}\right.$ e cerca de $100 \%$ de umidade relativa) para seis lotes de sementes de girassol

\begin{tabular}{|c|c|c|c|c|c|c|c|c|}
\hline \multirow{2}{*}{$\begin{array}{l}\text { Lote } \\
\text { no }\end{array}$} & \multirow{2}{*}{ Cultivar } & \multirow{2}{*}{$\begin{array}{c}\text { Idade das } \\
\text { sementes } \\
\text { (meses) }\end{array}$} & \multicolumn{6}{|c|}{$\begin{array}{l}\text { Porcentagens de germinação }\left({ }^{1}\right) \text { após os períodos de } \\
\text { tratamento (horas) }\end{array}$} \\
\hline & & & $\mathbf{0}$ & 24 & 48 & 72 & 96 & 120 \\
\hline $\begin{array}{l}1 \ldots \\
2 \ldots \\
3 \ldots \\
4 \ldots \\
5 \ldots \\
6 \ldots\end{array}$ & $\begin{array}{l}\text { Airelli } \\
\text { Florestal Cambá } \\
\text { IAC Anhandy } \\
\text { IAC Anhandy } \\
\text { Uruguai } \\
\text { Uruguai }\end{array}$ & $\begin{array}{r}28 \\
16 \\
16 \\
4 \\
52 \\
28\end{array}$ & $\begin{array}{l}45,5 \mathrm{~b}\left(^{2}\right) \\
16,9 \mathrm{c} \\
80,5 \mathrm{a} \\
82,8 \mathrm{a} \\
37,5 \mathrm{~b} \\
76,3 \mathrm{a}\end{array}$ & $\begin{array}{r}23,8 \mathrm{c} \\
6,8 \mathrm{~d} \\
84,5 \mathrm{a} \\
84,5 \mathrm{a} \\
10,2 \mathrm{~d} \\
61,8 \mathrm{~b}\end{array}$ & $\begin{array}{r}20,3 \mathrm{~b} \\
4,6 \mathrm{c} \\
78,0 \mathrm{a} \\
80,4 \mathrm{a} \\
12,0 \mathrm{~b} \\
74,1 \mathrm{a}\end{array}$ & $\begin{array}{r}7,4 \mathrm{~d} \\
0,8 \mathrm{e} \\
73,0 \mathrm{a} \\
60,3 \mathrm{~b} \\
0,9 \mathrm{e} \\
28,7 \mathrm{c}\end{array}$ & $\begin{array}{r}2,1 \mathrm{c} \\
1,0 \mathrm{c} \\
63,9 \mathrm{a} \\
51,3 \mathrm{a} \\
2,0 \mathrm{c} \\
25,8 \mathrm{~b}\end{array}$ & $\begin{array}{r}0,6 \mathrm{c} \\
0,3 \mathrm{c} \\
52,0 \mathrm{a} \\
42,7 \mathrm{a} \\
0,3 \mathrm{c} \\
18,3 \mathrm{~b}\end{array}$ \\
\hline $\mathrm{CV}$ & & & $10,16 \%$ & $7,93 \%$ & $8,36 \%$ & $10,67 \%$ & $15,96 \%$ & $15,49 \%$ \\
\hline
\end{tabular}

$\left({ }^{1}\right)$ Os dados foram transformados em arco seno $\sqrt{\%}$ para analise estatística. $\left({ }^{2}\right)$ Letras não-comuns na coluna indicam diferenças significativas detectadas pelo teste de Tukey ao nível de $5 \%$.

Observa-se que os lotes 3,4 e 6, que, no teste inicial de germinação, mostraram-se equivalentes, após 72 horas de envelhecimento acelerado, foram separados em grupos distintos quanto ao vigor, pois somente o lote 3 continuou a mostrar-se com a melhor qualidade fisiológica.

Esses dados são de grande importância para a tomada de decisão quanto à destinação a ser dada a determinado lote de sementes, porque deverão influir diretamente na possibilidade de seu armazenamento. 
Os resultados obtidos sugerem que: (a) não só é perfeitamente possível como importante a aplicação do teste de envelhecimento rápido em lotes de sementes de girassol; (b) o perfodo de 72 horas de permanência em câmara de envelhecimento acelerado é aquele que mais parece aproximar-se do ideal na aplicação do teste de envelhecimento rápido em sementes de girassol.

Essas conclusð̃es, no entanto, deverão ser comprovadas com o desenvolvimento das pesquisas mediante estudos de armazenagem e emergência, envolvendo maior número de lotes, pesquisas estas que já se encontram em andamento.

\section{SUMMARY \\ SUNFLOWER SEEDS: \\ PRELIMINARY OBSERVATIONS ABOUT THE ACCELERATED AGING TEST}

Six lots of sunflower (Helianthus annuus L.) seeds were submitted to the accelerated aging test at the temperature of $42^{\circ} \mathrm{C}$ and $100 \%$ relative humidity, for periods of $24,48,72,96$ and 120 hours. The germination capacity of the seeds decreased as the period of exposure increased. The best period to discriminate the physiological quality of the sunflower seeds used was 72 hours.

Index terms: seeds; sunflower; Helianthus annuas L.; vigor; aging.

\section{REFERÊNCIAS BIBLIOGRÁFICAS}

BRASIL. Ministério da Agricultura. Divisão de Sementes e Mudas. Regras para análise de sementes. Brasília, 1976. 188p.

GOMES, F. P. Curso de estatística experimental. 4.ed. Piracicaba, Nobel, 1970. 480p.

POPINIGIS, F. Fisiologia de sementes. Brasília, AGIPLAN/Ministério da Agricultura, 1974. 78p.

SOMERS, D. A. ; ULLRICH, S. E. \& RAMSAY, M. F. Sunflower germination under simulated drought stress. Agronomy Journal, 75:570-572, 1983.

ZIMMERMAN, D. C. \& ZIMMER, D. E. Influence of harvest date and freezing on sunflower seed germination. Crop Science, 18:479-481, 1978. 